\title{
Fatty acid homeostasis in honey bees (Apis mellifera) fed commercial diet supplements
}

\author{
Vanessa Corby-Harris ${ }^{1}{ }^{\oplus}$, Meghan M. BennetT ${ }^{1}$, Megan E. Deeter ${ }^{1,2}$, \\ Lucy SNYder ${ }^{1}$, Charlotte Meador ${ }^{1}$, Ashley C. WelcherT ${ }^{1,2}$, Amelia Hoffman ${ }^{1}$, \\ Bethany T. OBERNESSER ${ }^{1,2}$, and Mark J. CARROLL ${ }^{1}$ \\ ${ }^{1}$ Carl Hayden Bee Research Center, USDA-ARS, Tucson, AZ 85719, USA \\ ${ }^{2}$ Department of Entomology, University of Arizona, Tucson, AZ 85721, USA
}

Received 15 February 2021 - Revised 7 September 2021 - Accepted 21 September 2021

\begin{abstract}
Honey bees obtain lipids from pollen or commercial supplements. These supplements do not fully support colony health. We tested the hypothesis that supplements are deficient because they lack essential fatty acids (EFAs). The five supplements we tested had low linolenic $(\omega 3)$ acid and were unbalanced $(\omega 6: \omega 3>6)$ compared to natural pollen. We selected two of these supplements for further study because they had different levels of individual EFAs and different $\omega 6: \omega 3$ ratios. Bees from hives fed these different supplements had equivalent tissue EFA levels. In choice assays, hives fed these different supplements were presented with flours with various absolute and relative levels of EFAs. We saw no difference in foraging preference. Rather, all hives preferred flours with small grain size and high protein to lipid ratios. We conclude that bees balance their internal EFAs and that differential colony nutrition does not affect foraging preference. The data also argue for more linolenic $(\omega 3)$ acid in commercial supplements.
\end{abstract}

Apis mellifera / honey bee / nutrition / fatty acid / supplement

\section{INTRODUCTION}

Honey bees exploit a range of floral resources to meet their protein, lipid, carbohydrate, and micronutrient needs. These floral resources are not always available due to the nature of commercial migratory beekeeping (i.e., holding yards), monocultures, drought, or seasonal pollen dearths. Colonies are routinely fed artificial commercial diets to supplement their pollen intake when forage is unavailable or limited. These supplements must provide the lipids and protein that would normally come from natural pollen. Despite many years of

Corresponding author: V. Corby-Harris, vanessa.corby@usda.gov

Manuscript editor: James Nieh studying honey bee nutrition (Haydak 1970; Manning 2018; Wright et al. 2018), we have yet to develop a supplemental diet that supports colonies beyond 2-3 brood cycles (DeGrandiHoffman et al. 2016). A more complete understanding of how these supplements compare to pollen and how bees acquire and assimilate dietary nutrients might offer clues to improve these supplements.

Pollen is complex in its outer structure, its attractiveness to pollinators, and the nutrition it provides to honey bees. Bees are attracted to features of the pollen itself, such as the odor, outer lipid coat, or grain size, and to floral traits (Dobson 1988; Dobson and Bergström 2000; Lunau 2000; Lundin et al. 2019; Pernal and Currie 2002; Rowe et al. 2020). Much of pollen 
nutrition research to date focuses on protein and amino acids rather than lipids, which play key roles in energetic and physiological homeostasis (Brodschneider and Crailsheim 2010; Crailsheim 1990; de Groot 1953; Haydak 1970; Herbert et al. 1977; Manning 2001, 2008; Manning et al. 2007; Standifer 1967; Vanderplanck et al. 2020). Lipids are emerging as a critical aspect of honey bee nutrition because of their positive effect on honey bee health (Annoscia et al. 2017; Crone and Grozinger 2021; Stabler et al. 2021).

Nutrients that bees obtain from their diet and cannot synthesize are termed "essential" and include the essential fatty acids (EFAs) linoleic (18:2n-6, $\omega 6)$ and $\alpha$-linolenic acid (18:3n-3, $\omega 3)$. On average, these EFAs make up $43 \%$ of the total fatty acids (TFAs) measured in pollen (Online Resource Table I; (Arien et al. 2015; Avni et al. 2014; Corby-Harris et al. 2018; DeGrandi-Hoffman et al. 2021, 2018; Manning 2001; Robinson and Nation 1970; Saa-Otero et al. 2000)). They are also relatively balanced in pollen, with a $\omega 6: \omega 3$ ratio close to 0.8 . Both EFAs are important individually and with respect to their $\omega 6: \omega 3$ ratio. Bees fed diets deficient in linolenic $(\omega 3)$ acid have smaller hypopharyngeal glands and decreased learning acquisition (Arien et al. 2015). Further, consumption of high $\omega 6: \omega 3$ ratio diets causes increased mortality and decreased brood rearing ability (Arien et al. 2020).

Colonies may adjust their foraging behavior to rescue nutritional deficiencies, but the evidence for this is somewhat mixed. Honey bee colonies do tend to focus on certain pollens, but these pollens are often not nutritious (Cornman et al. 2015; Leonhardt and Blüthgen 2012; McMinn-Sauder et al. 2020; Melin et al. 2020; Richardson et al. 2019; Roulston and Cane 2000; Smart et al. 2017; van der Moezel et al. 1987). Pernal and Currie $(2001,2002)$ found that foragers do not recruit to pollens that rescue previous protein deficiencies, but instead respond to cues such as pollen odor and grain size. Beekman et al. (2016) similarly found that bees do not dance more for more proteinrich diets compared to protein poor diets. It is unclear how foragers would perceive that specific nutrients are in short supply, since it is the nurses and larvae, not foragers, that consume most of the pollen and its nutrients. In paired choice assays, nurse bees did not prefer diets that promoted nurse hypopharyngeal gland development (Corby-Harris et al. 2018). In contrast, other studies show that honey bees do collect diets and pollen according to nutritional cues. Paoli et al. (2014) showed that workers consume certain ratios of protein and carbohydrates in

\section{Table I.}

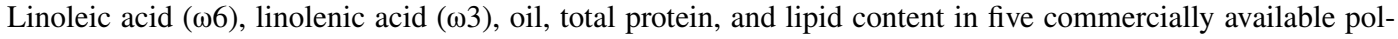
len supplements.

\begin{tabular}{|c|c|c|c|c|c|c|c|c|c|}
\hline \multirow{2}{*}{$\begin{array}{l}\text { Commercial sup- } \\
\text { plement }\end{array}$} & \multicolumn{2}{|l|}{$\omega 6$} & \multicolumn{2}{|l|}{$\omega 3$} & \multirow[t]{2}{*}{$\omega 6: \omega 3$} & \multirow[t]{2}{*}{ oil \% } & \multirow{2}{*}{$\begin{array}{l}\text { Protein }(\mu \mathrm{g} / \mathrm{mg} \\
\text { diet) }\end{array}$} & \multirow{2}{*}{$\begin{array}{l}\text { Lipid } \\
(\mu \mathrm{g} / \mathrm{mg} \\
\text { diet })\end{array}$} & \multirow[t]{2}{*}{$\mathrm{P}: \mathrm{L}$} \\
\hline & $\mu \mathrm{g} / \mathrm{mg}$ diet & $\% \mathrm{TFA}$ & $\mu \mathrm{g} / \mathrm{mg}$ diet & $\% \mathrm{TFA}$ & & & & & \\
\hline $\begin{array}{l}\text { MegaBee (low- } \\
\text { EFA) }{ }^{1}\end{array}$ & 13.97 & 53.3 & 0.74 & 2.8 & 18.8 & 2.6 & $2146 \pm 347$ & $39 \pm 2$ & 55 \\
\hline $\begin{array}{l}\text { UltraBee (high- } \\
\text { EFA) }\end{array}$ & 35.24 & 54.5 & 4.85 & 7.5 & 7.3 & 6.6 & $2303 \pm 247$ & $65 \pm 3$ & 35 \\
\hline AP23 & 44.79 & 50.6 & 3.28 & 3.7 & 13.6 & 8.9 & Not measured & & \\
\hline BeePro & 24.11 & 52.9 & 3.94 & 8.6 & 6.1 & 4.6 & & & \\
\hline BroodBuilder & 14.01 & 51.3 & 1.54 & 5.6 & 9.1 & 2.8 & & & \\
\hline
\end{tabular}

${ }^{1}$ Diets fed to hives in this study. Values correspond to diets without $5 \%$ pollen added 
a caste-specific manner. Stabler et al. (2021) also found that nurse-aged bees balance their dietary intake to reflect a lower protein to lipid ratio, which maximizes individual health. At the colony level, hives fed pollens or artificial diets deficient in certain amino acids, minerals, or EFAs prefer diets that rescue this deficiency (Bonoan et al. 2018; Bonoan et al. 2017; Hendriksma and Shafir 2016; Hendriksma et al. 2019; Zarchin et al. 2017). For example, colonies fed natural pollens deficient in either linoleic ( $\omega 6)$ or linolenic ( $\omega 3)$ acid exhibit higher waggle dance rates toward pollens that rescue this deficiency (Zarchin et al. 2017).

Here, we sought to better understand the downstream effects of diet (natural pollen or commercial pollen substitutes) on colony health and behavior through the lens of EFAs. We first assessed the EFAs in different commercial supplements, along with total lipid and protein levels. Two of these supplements were selected for further study based on their EFA levels: the high- or low-EFA supplement. We gathered information on tissue EFAs in bees sampled from these colonies to ask how these EFAs are assimilated in bee tissue. We hypothesized that bees sampled from high-EFA hives would have more EFAs in their tissues than those from low-EFA hives. Next, given previous research suggesting that colonies forage for diets that rescue previous fatty acid deficiencies (Zarchin et al. 2017) and the benefits of a balanced diet to honey bee health (Arien et al. 2018, 2020), we assessed the foraging behavior of hives fed low- or high-EFA supplements. Hives were presented with an array of choice flours with varying levels of both EFAs. We hypothesized that (1) low-EFA hives would make more visits to choice flours with high levels of EFAs. Further, if hives forage in a way that balances their EFA intake towards an $\omega 6: \omega 3$ ratio of one, we hypothesized that hives fed the more unbalanced low-EFA supplement would make more visits to choice flours with more linolenic ( $\omega 3)$ acid and with lower $\omega 6: \omega 3$ ratios compared to the high-EFA hives.

\section{MATERIALS AND METHODS}

\subsection{Colonies}

Thirteen colonies were used in the experiments described below. Three were maintained outdoors and ten were enclosed. Each colony was headed by an open-mated Apis mellifera queen from a Northern California breeder. All colonies consisted of approximately 5-7 frames of adult bees, brood of all stages, and food stores. The hives were monitored regularly throughout the course of the experiment to ensure that the queen was alive and laying eggs.

\subsection{Feeding commercial supplemental diets}

To select two diets with high or low levels of fatty acids for further study, we measured the fatty acids in five commercial protein supplements. The supplements were analyzed for fatty acids using the GC-FID fatty acid methyl ester (FAME) analysis described in Corby-Harris et al. (2018). Absolute ( $\mu \mathrm{g} / \mathrm{mg}$ diet) and relative (\%TFA) amounts of linoleic $(\omega 6)$ and linolenic ( $\omega 3)$ acid were quantified, using an internal C17:0 standard not found in honey bees and a panel of C14-C24 fatty acid standards. From this larger pool of tested supplements, MegaBee (megabee.com) was selected as the "low-EFA" diet and UltraBee (Mann Lake Ltd.) the "highEFA" diet. Total soluble protein and lipid in the high- and low-EFA supplements were measured using a Bradford assay and a sulfo-phosphovanillin assay (Van Handel 1985; Vaudo et al. 2020). Samples were weighed prior to determining the protein and lipid levels.

Ten hives were placed into screened enclosures so that we could be sure that they consumed only the supplement and so we could closely observe their behavior (see below). Each enclosure consisted of a semi-circular building (Online Resource Figure 1) that was covered with $40 \%$ black shade cloth (www. greenhousemegastore.com) and further divided 

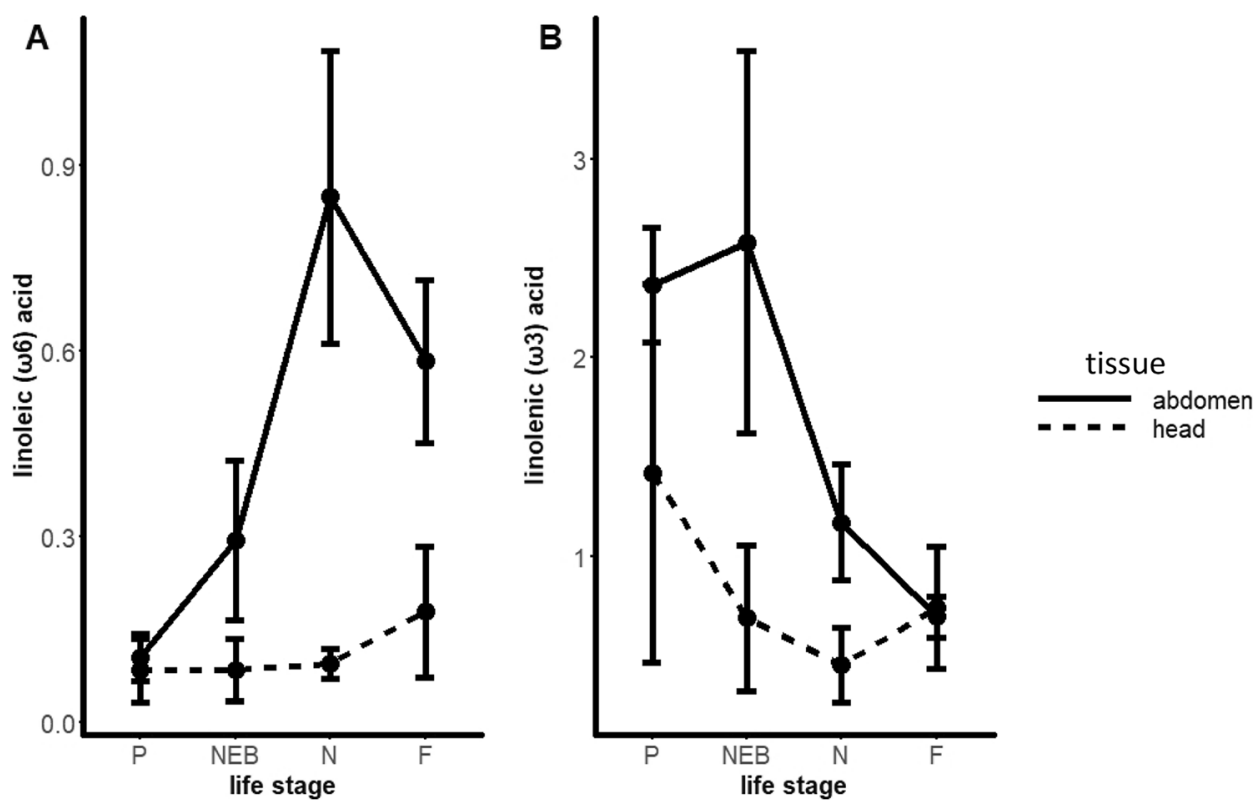

Figure 1. EFAs by life stage in outdoor hives. Average amounts $(\mu \mathrm{g} / \mathrm{mg}) \pm \mathrm{SE}$ of A linoleic $(\omega 6)$ and B linolenic $(\omega 3)$ acids are shown for pupae (P), newly emerged bees (NEB), nurses (N), and foragers (F). Three hives were sampled. Abdomens had more EFAs per unit of tissue weight than heads (linoleic acid $(\omega 6): p=0.0012$; linolenic acid $(\omega 3): p=0.0090)$.

into 10 separate bays $(3.5 \mathrm{~m} \times 5.3 \mathrm{~m})$ with EcoNet 100,400 insect screen (Svensson). The hives were placed in a north-south orientation, with the entrance facing north. Each bay contained one hive.

Hives were moved into the enclosures between July 17, 2019, and July 24, 2019. All hives were normalized for brood and frames of bees before the start of the experiment. In the enclosures and throughout the length of the experiment (July-October 2019), the hives were provided with fresh water ad libitum from gravity feeders (Miller Manufacturing Company) placed at the opposite end of the enclosure from the hive. Each hive was provided with one honey frame throughout the length of the study; frames were replenished as needed to ensure a constant supply of carbohydrates.

Hives were fed the low- ( $N=5$ hives) or highEFA ( $N=5$ hives) supplement for 3 weeks (one brood cycle) before the choice trials commenced. The bees consumed their existing pollen stores within 1 week of going into the enclosure. The supplements were mixed evenly with $5 \%$ natural corbicular pollen (www.bulkfoods.com) and were provided in loose dry form in dishes at the opposite end of the enclosure. The $5 \%$ pollen increased forager attraction to the supplements (Hendriksma and Shafir 2016). The supplements were provided to the hives for the duration of the experiment (July-October). The supplement was replenished three times weekly and was available at all times except for during the choice trials (see below). We noted what hives consumed all of the supplements, but the supplement was never weighed to obtain a quantitative measure of consumption.

\subsection{Fatty acid methyl ester analysis}

The fatty acids in the choice diets and bee samples were converted into their fatty acid methyl 
ester (FAME) equivalents and quantified by EI GC-MS as described in DeGrandi-Hoffman et al. (2018) after Seppänen-Laakso et al. (2002). Samples were quantified relative to $50 \mu \mathrm{g}$ of a cis10-heptadecenoic acid internal standard. FAME equivalents of linoleic $(\omega 6)$ and linolenic $(\omega 3)$ acids were identified and quantified by comparing the retention times and mass spectra with known amounts of authentic esterified fatty acid standards (Sigma). Weights of the tissues and choice diets were obtained prior to conducting the FAME analysis. Tissues were blotted on tissue paper to remove excess fluid prior to weighing. EFA content was expressed in terms of $\mu \mathrm{g}$ EFA per $\mathrm{mg}$ of bee tissue or choice diet.

\subsection{Do bee tissue fatty acids vary across tissues, life stages, or with diet?}

Bees from hives in the screen enclosures that were fed high- or low-EFA supplements were evaluated for tissue fatty acids. After the last choice trial, queens, larvae, recently $(<48 \mathrm{~h})$ capped worker larvae, pink-eyed worker pupae, newly emerged adult workers (NEBs), nurses, and foragers were sampled. One hive fed the high-EFA diet failed prior to sampling (sample sizes reported in Online Resource Table IV). Nurses were bees that had their heads in a cell containing young larvae for $\geq 5 \mathrm{~s}$. Foragers were bees that were visiting the choice diets (enclosures only). Samples were collected into liquid nitrogen and stored at $-80{ }^{\circ} \mathrm{C}$ until they were prepared for lipid analysis. Excluding queens and larvae, heads and abdomens were separated. Five pupae, NEBs, nurses, and foragers and three larvae were sampled from each colony. Samples from each hive were pooled into one tube per colony separated for each caste or developmental phase. The queen was also sampled from each colony. In adult workers and queens, the GI tract was removed. Pupal GI tracts were left intact, but did not contain pollen due to the defecation that happens at the last larval molt. One sample of forager heads and pupae heads from two different hives fed the low-EFA diet yielded a poor extraction and were eliminated from the data set.

In addition to the samples from the hives in enclosures, similar samples were taken from three hives in the apiary that were foraging on natural outdoor resources during the fall of 2019. For these hives, foragers were bees that were returning to the hive with pollen on their corbiculae. Queens were not sampled from the outdoor hives.

To gain a picture of the EFA levels in a natural field scenario, we asked whether EFAs differed due to life stage (pupae, NEBs, nurses, and foragers) and tissue type (head and abdomen) in the three hives kept outdoors with access to natural pollen. Linoleic $(\omega 6)$ acid and linolenic $(\omega 3)$ acid were log transformed, and the data were analyzed using an ANOVA. Life stage, tissue type, and the interaction between life stage $\times$ tissue type were the dependent variables. EFAs were measured for whole larvae sampled from outdoor hives, but we did not compare the larvae to the other life stages because they were not separated into heads and abdomens. EFA ratios were calculated for each sample and reported as average values for each life stage and tissue type.

We next addressed whether supplement type (high- or low-EFA) influenced bee tissue EFAs, considering only the hives kept in the screened enclosures. We first asked whether supplement type influenced the amount of linoleic $(\omega 6)$ or linolenic $(\omega 3)$ acids extracted from whole queens. The queen data did not fit the assumptions of a linear model (unequal variances, non-normal error residuals) and were analyzed using a non-parametric Wilcoxon analysis. We asked whether supplement type influenced the EFA levels in whole larvae using a $t$-test. For the pupae, NEBs, nurses, and forager data set, we tested whether the log-transformed linoleic $(\omega 6)$ or linolenic $(\omega 3)$ acid levels were influenced by supplement type, life stage, tissue type (head or abdomen), and all two- and three-way interaction terms using an ANOVA. EFA ratios were calculated for each sample and reported as average values for each supplement type, life stage, and tissue type. 


\subsection{Do hives prefer certain choice flours based on the supplement that they were fed?}

Previous work shows that bees will forage for diets that rescue previous dietary deficiencies and that foragers select diets based on grain size, total lipids, total protein, $\mathrm{P}: \mathrm{L}$ ratio, $\omega 3, \omega 6$, and $\omega 3: \omega 6$ ratio (Altaye et al. 2010; Arien et al. 2018, 2015; Pernal and Currie 2002; Pirk et al. 2010; Stabler et al. 2021; Vaudo et al. 2020; Zarchin et al. 2017). To test these ideas, we presented bees that were fed the high- or low-EFA diets with nine choice flours (almond, cashew, chia, chickpea, peanut, red lentil, sunflower, walnut, or white bean) and measured their visitation to each flour. These choice flours were initially selected according to their levels of linoleic $(\omega 6)$ and linolenic $(\omega 3)$ acids, obtained from the USDA Agricultural Research Service FoodData Central database (fdc.nal.usda.gov). The flours were ground using a coffee bean grinder, yielding grains that we measured using a dissecting scope at $10 \times$ magnification. The length and width of 30 grains per choice diet were measured using the Leica Application Suite software. Grain size was the greater of these two measures. Natural corbicular pollen was mixed into each of the ground choice flours to a final concentration of 5\% w/w (Hendriksma and Shafir 2016), which increased the attractiveness of the flours. Samples were taken from each choice diet $(+5 \%$ pollen) and weighed before determining their total protein and lipid content using a Bradford assay and a sulfo-phospho-vanillin assay (Van Handel 1985; Vaudo et al. 2020). Fatty acid content was measured for each of the choice flours with the $5 \%$ pollen added.

We conducted six choice trials to compare the foraging preference of hives fed the high- or low-EFA supplements. On the morning of each trial, the loose supplement was removed and each hive was immediately presented with two trays containing three petri dishes of each flour, for a total of 27 petri dishes (Online Resource Figure 2). The dishes were randomly distributed across the two trays and their position changed with each trial. The trays were placed in the exact same place as the supplement, and the supplement was replaced immediately after the trial was complete. The choice trials were conducted approximately each week (August 23, September 4, September 11, September 18, September 27, October 2). Photos of each tray were taken at 5 -min intervals until one of the petri dishes was empty or up to $2 \mathrm{~h}$ total, whichever came first. At that point, no more photos were taken of that hive. For each trial and choice flour, the number of visits was determined by counting the number of bees present on each choice flour across all photos. Per-trial visitation to each choice flour was calculated by dividing the number of visits to the choice flour by the number of total foraging visits to all diets summed. This normalized the visitation data for hive strength. Total visitations across all trials were calculated in a similar manner and by summing the visits to each flour across trials.

We first asked whether colonies fed low-EFA supplements preferred certain choice flours compared to colonies fed high-EFA supplements. The per-trial visitation data was square root transformed and analyzed using a repeated measures MANVOA with an unstructured covariance matrix. The dependent variable was the percent of total visits, and the independent variables were supplement fed, choice flour, and supplement $\times$ choice flour. We were particularly interested in the effect of supplement $\times$ choice flour, which would indicate that forager preference for certain choice flours depended on what supplement the hive was fed.

We also asked whether certain qualities of the choice diets (grain size, total lipids, total protein, $\mathrm{P}: \mathrm{L}$ ratio, $\omega 3, \omega 6, \omega 3: \omega 6$ ratio) attracted foragers irrespective of the supplements that they were fed (i.e., for all colonies). These qualities have been shown to influence foraging choice (Altaye et al. 2010; Arien et al. 2018, 2015; Pernal and Currie 2002; Pirk et al. 2010; Stabler et al. 2021; Vaudo et al. 2020; Zarchin et al. 2017). Many of these qualities were inherently correlated (Online Resource Table II), so we used principal components analysis (PCA) to examine how each quality explained the differences among the choice flours after the correlations were 
accounted for. The rda function in the vegan package ((Oksanen et al. 2020); R version 3.6.1) was used to examine the standardized response variables $($ mean $=0 ; \mathrm{SD}=1)$. The first two principal components (PCs) were plotted. We then calculated the standardized correlation of each variable to each PC axis to determine how qualities of each choice diet influenced the variation in forager preference, focusing on $\mathrm{PC} 1$.

\section{RESULTS}

\subsection{Commercial supplements varied in nutrient content}

Of the five commercial pollen supplements tested and in terms of $\mu \mathrm{g} / \mathrm{mg}$ of supplement, the high-EFA diet had the highest linolenic acid ( $\omega 3$ ) content, while the low-EFA diet had the lowest (Table I). The high-EFA diet contained $2303 \mu \mathrm{g} \pm 247 \mathrm{SE}$ protein and $65 \mu \mathrm{g} \pm 3 \mathrm{SE}$ lipids per mg of diet (Table I). The low-EFA diet contained $2146 \mu \mathrm{g} \pm 347 \mathrm{SE}$ protein and $39 \mu \mathrm{g} \pm 2$ SE lipids per mg of diet. Their protein to lipid ratios also differed: the high-EFA supplement $(\mathrm{P}: \mathrm{L}=35)$ had a lower ratio than the low-EFA supplement $(\mathrm{P}: \mathrm{L}=55)$.

\subsection{Choice flours varied in their grain size and nutrient content}

The grain size and nutrient levels of the nine choice flours are presented in the Online Resource Table III. The choice flours had a mean grain size of $0.77 \mathrm{~mm} \pm 0.31 \mathrm{SD}$. The choice flour with the largest grain size was walnut $(1.20 \mathrm{~mm} \pm 0.08 \mathrm{SE})$, and the smallest was chickpea $(0.33 \mathrm{~mm} \pm 0.02 \mathrm{SE})$. The red lentil was lowest in protein $(1150 \mu \mathrm{g} / \mathrm{mg} \pm 154 \mathrm{SE})$, while white bean was the highest $(2408 \mu \mathrm{g} /$ $\mathrm{mg} \pm 763 \mathrm{SE})$. The sunflower was highest in lipids $(349.0 \mu \mathrm{g} / \mathrm{mg} \pm 21.6 \mathrm{SE})$, while the white bean $(17.1 \mu \mathrm{g} / \mathrm{mg} \pm 0.56 \mathrm{SE})$ was the lowest in lipids. Protein to lipid (P:L) ratios of the choice flours varied between 4 (almond) and
142 (white bean). Linoleic ( $\omega 6)$ acid was lowest in the white bean $(11.27 \mu \mathrm{g} / \mathrm{mg})$ and highest in walnut $(488.05 \mu \mathrm{g} / \mathrm{mg}$ ). Linolenic ( $\omega 3)$ acid was lowest in the red lentil $(7.99 \mu \mathrm{g} / \mathrm{mg})$ and highest in walnut $(114.11 \mu \mathrm{g} / \mathrm{mg})$. The $\omega 6: \omega 3$ ratio in the choice flours ranged from 0.68 (chia) to 4.28 (walnut).

\subsection{Bee tissue EFAs differed among tissues and life stages but not supplement type}

In outdoor hives, both EFAs differed with respect to tissue type (linoleic acid $(\omega 6)$ : $F_{1,16}=15.45, p=0.0012$; linolenic acid $(\omega 3)$ : $\left.F_{1,16}=8.82, p=0.0090\right)$ and were higher in the abdomen than the head (Figure 1, Online Resource Table IV). Linoleic acid

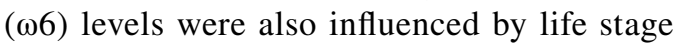
$\left(F_{3,16}=7.86, p=0.040\right)$, but life stage was not a significant predictor of linolenic acid ( $\omega 3)$ levels. The tissue type $\times$ life stage interaction term was not significant for either EFA. The average amount of linoleic $(\omega 6)$ and linolenic $(\omega 3)$ acid in whole larvae was $0.210 \mu \mathrm{g} / \mathrm{mg} \pm 0.051 \mathrm{SE}$ and $5.694 \mu \mathrm{g} / \mathrm{mg} \pm 2.459 \mathrm{SE}$, respectively (Online Resource Table IV). The $\omega 6: \omega 3$ ratios for the bees sampled from the outdoor hives are reported in Online Resource Table IV.

In the enclosed hives, supplement type influenced tissue EFAs in only one case. Queens sampled from high-EFA hives had more linoleic acid $(\omega 6)$ than the low-EFA hives $\left(X_{1}^{2}=6.00 ; p=0.014\right.$; Online Resource Table IV). The EFAs in whole larvae did not differ with supplement type (Table II). For the pupae, NEB, nurse, and foragers, life stage influenced both the linoleic $\left(\omega 6 ; F_{3,54}=17.90\right.$, $p<0.0001)$ and linolenic $\left(\omega 3 ; F_{3,54}=7.71\right.$, $p=0.0002$ ) acid levels (Figure 2). There was no effect of tissue type, supplement type, or any of the interaction terms on pupae, NEB, nurse, or forager EFAs. The $\omega 6: \omega 3$ ratios for the bees sampled from the hives fed the highor low-EFA supplements are reported in Online Resource Table IV. 

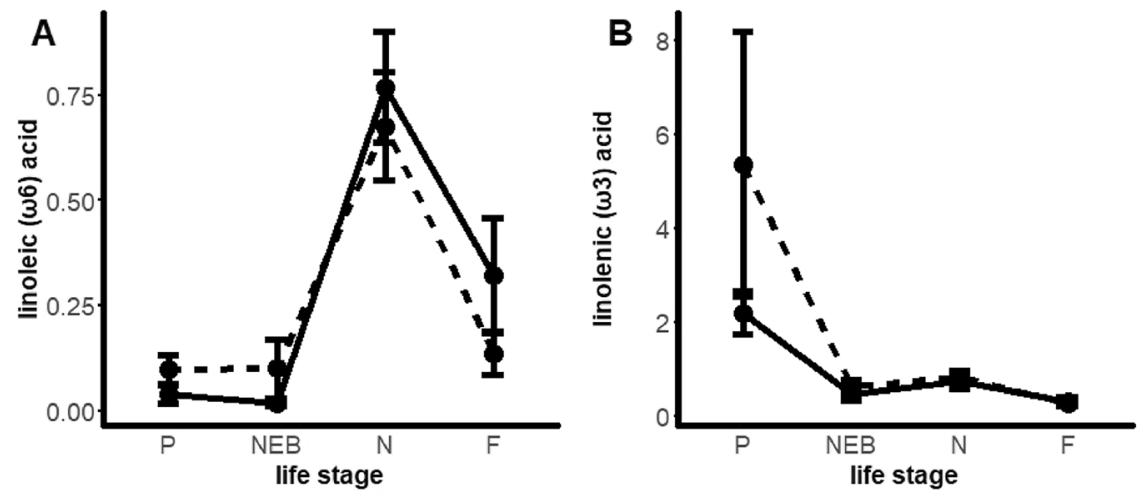

supplement
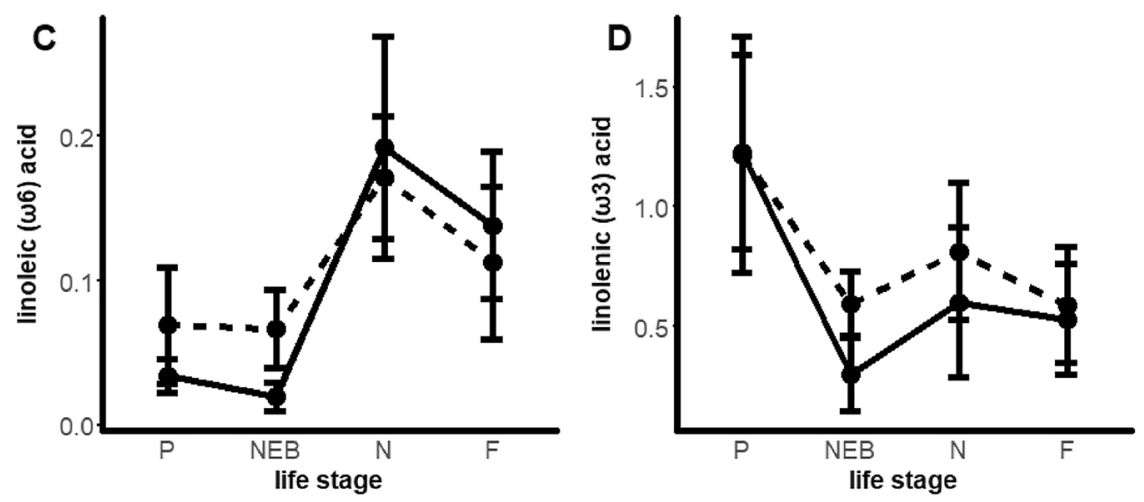

Figure 2. Mean amounts of EFAs by life stage in indoor hives fed high- or low-EFA supplements. Average amounts $(\mu \mathrm{g} / \mathrm{mg}) \pm \mathrm{SE}$ of $(\mathrm{A}, \mathrm{C})$ linoleic $(\omega 6)$ and $(\mathrm{B}, \mathrm{D})$ linolenic $(\omega 3)$ acids are shown for pupae $(\mathrm{P})$, newly emerged bees $(\mathrm{NEBs})$, nurses $(\mathrm{N})$, and foragers $(\mathrm{F})$. Abdomen levels are shown in the top panels $(\mathbf{A}, \mathbf{B})$, and head levels are shown in the bottom panels $(\mathbf{C}, \mathbf{D})$. Please note the different scales on the $y$-axes. Tissue EFAs differed among life stages $\left(\omega 6: F_{3,54}=17.90, p<0.0001 ; \omega 3: F_{3,54}=7.71, p=0.0002\right)$. There was no effect of tissue type, diet, or any of the interaction terms on pupae, NEB, nurse, or forager EFAs.

\subsection{Foraging choice was influenced by macronutrient content and grain size}

Most but not all hives consumed all of the supplemental diet that was provided. Hives tended to completely consume the high-EFA supplement more frequently than the low-EFA supplement.

Hives did not prefer certain choice flours based on the supplement that they were fed. Visitation was influenced by choice flour $\left(F_{8,72}=73.59, p<0.0001\right.$; Figure 3$)$, but we saw no significant effect of supplement type or the interaction term. Averaged across all six trials and supplement type, colonies preferred the white bean flour the most, followed by the red lentil and chickpea, next the sunflower, peanut, and chia, the almond, and the walnut and cashew the least (white bean $>$ red lentil, chickpea $>$ sunflower, peanut, chia $>$ almond $>$ walnut, cashew; Figure 3, Online Resource Table III). For the PCA, the first two PCs explained nearly $75 \%$ of the variation among the choice flours ( $\mathrm{PC} 1=45.3 \%$, $\mathrm{PC} 2=29.5 \%$; Figure 4 ). In plotting these PCs, flours with the highest forager visitation (white bean, red lentil, and chickpea) were at the higher end of the axis. Grain size (correlation $=0.97$ ) and $\mathrm{P}: \mathrm{L}$ ratio (correlation $=0.86$ ) showed the strongest correlation with PC1. Flours with the smallest grain sizes and the largest $\mathrm{P}: \mathrm{L}$ ratio had the most foraging 
Fatty acid homeostasis in honey bees (Apis mellifera) fed commercial diet supplements

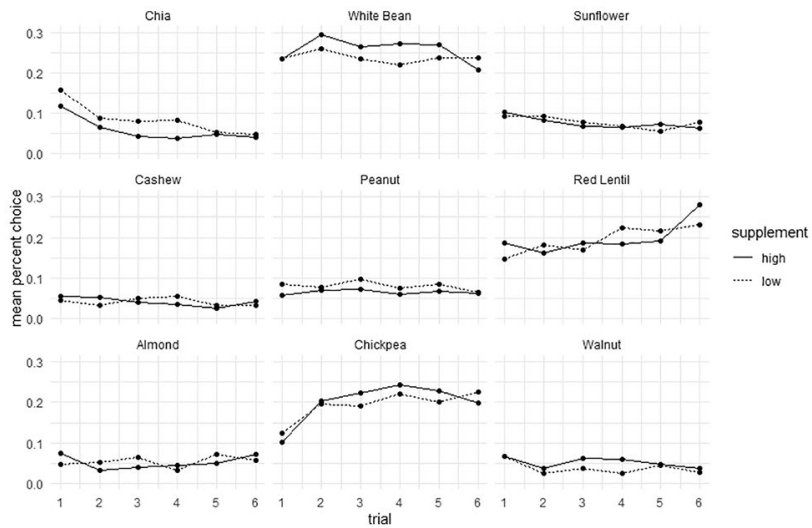

Figure 3. Mean percent of foragers visiting each choice flour when fed high- or low-EFA supplemental diets. Choice flours are ordered in from lowest $\omega 6: \omega 3$ ratio (chia) to highest ratio (walnut). Choice flour $(p<0.0001)$ significantly influenced the proportion of foraging visits.

visits (Figure 4, Online Resource Table II). the remaining variables were negatively corTotal protein was also positively correlated related with PC1 (lipid correlation $=-0.70$, with PC1 (protein correlation $=0.63$ ), while $\omega 6: \omega 3=-0.30, \omega 6=-0.68, \omega 3=-0.53$ ).



Figure 4. PCA of choice flours. PC1 and PC2 explained approximately $75 \%$ of the total variation among the choice flours. Each point represents one of the choice flours. The points are labeled with the P:L ratio of each flour included in parentheses. The points are colored according to the total percent of visits foragers made to each flour and sized according to grain size (see Online Resource Table IV for values). Please note that the point representing the chickpea flour is circled because it has a small grain size $(0.3 \mathrm{~mm})$. Chickpea flour received $19.7 \%$ of the total visits. 


\section{DISCUSSION}

Despite many years of research on pollen supplements and bee nutrition, we have yet to design a suitable pollen supplement that supports hive health when natural pollen is limited. Our ultimate goal with this study was to employ chemical analyses of diets and bee tissues combined with observations of colony foraging behavior to lend insight into how supplements might be improved. We found that commercial supplements have small amounts of linolenic $(\omega 3)$ acid and are unbalanced $(\omega 6: \omega 3>6)$ compared to natural pollen. Further study of how fatty acids are obtained and assimilated showed that bees from hives fed high- or low-EFA supplements had largely similar tissue EFA levels. In choice tests, hives fed low-EFA supplements did not make more foraging visits to flours that rescued this deficiency compared to the highEFA hives. Instead, there was an overall preference for flours with smaller grain sizes with a high P:L ratio.

An initial survey of the EFAs in commercial pollen supplements yielded important information on the levels of EFAs in these diets. All supplements that we tested contained more linoleic $(\omega 6)$ and less linolenic ( $\omega 3)$ acid than pollen (Online Resource Table I; (Arien et al. 2015; Avni et al. 2014; Corby-Harris et al. 2018; DeGrandi-Hoffman et al. 2021, 2018; Manning 2001; Robinson and Nation 1970; Saa-Otero et al. 2000)). These low linolenic $(\omega 3)$ acid values were similar to that measured in pollens from Eucalyptus sp. (Arien et al. 2015; Somerville 2005) and Zea mays (Höcherl et al. 2012; Standifer 1967), which tend to be less nutritious for bees. Our results suggest that even the most linolenic ( $\omega 3)$ acid-rich supplement may be deficient in this critical nutrient. The supplements were also imbalanced, with $\omega 6: \omega 3$ ratios $>6$, compared to the much lower ratios found in natural pollens $(\sim 0.8)$. Although we caution that more testing is needed to confirm the amount of fatty acids in these diets, these data suggest that commercial supplements might be improved by adding linolenic ( $\omega 3)$ acid in a way that keeps the $\omega 6: \omega 3$ ratio low.
We identified two supplements for further testing. Relative to each other and per milligram of diet, the high-EFA supplement had 2.5-fold more linoleic $(\omega 6)$ acid and 6.5-fold more linolenic ( $\omega 3)$ acid. The low-EFA supplement also had a higher $\omega 6: \omega 3$ ratio than the high-EFA supplement, suggesting that it was more unbalanced relative to natural pollen. The supplements were roughly equivalent in terms of soluble protein, but these levels were much higher than what is normally found in pollen (Vaudo et al. 2020). The low-EFA supplement had less total lipids per milligram of diet and a higher P:L ratio compared to the high-EFA supplement. Both the high- and low-EFA supplements had total lipids within the range of those found in plant pollen, but were skewed upwards in terms of P:L ratio (Vaudo et al. 2020). We used the more gentle chemical lysis method outlined in Vaudo et al. (2020) to estimate the total lipids and proteins in the supplements (and choice flours, discussed below). While this enabled a comparison between our data and Vaudo et al. (2020), the true amounts of total protein and lipids may actually be higher because, in our experience, this method does not fully lyse the pollen grain. In contrast, we lysed the pollen grain via bead beating for our fatty acid measurements. This resulted in some samples having more fatty acids than total lipid, which is not possible. This highlights the importance of methodology, but does not influence the main findings of the present study where the treatments were based on the relative differences between the high- and lowEFA supplements. Lastly, we again note that pollen was mixed into the loose dry supplement fed to the bees in order to attract foragers and encourage consumption. This added pollen may have impacted the nutritional composition of the supplements fed to the bees, but not their relative nutritional differences.

Outdoor hives were sampled to assess the natural levels of EFAs in bee tissues. In these outdoor hives, both EFAs were affected by tissue type but not life stage, with EFAs more concentrated in the abdomen compared to the head. This is consistent with the abdominal fat body's role as a lipid storage organ, but disagrees with 
findings from Arien et al. (2015), who found that brains contained more fatty acids than the rest of the body. This higher concentration of fatty acids in the brain is consistent with the documented role of linolenic $(\omega 3)$ acid in olfaction (Arien et al. 2015). The discrepancy between the present study and Arien et al. (2015) may be because we used whole heads, not brains. Other less lipid-rich head tissue could have skewed our measures downward. EFA levels were also largely similar across life stages. This was also somewhat unexpected because nurse bees contain more fat than foragers in their abdomen and hypopharyngeal glands (Corby-Harris et al. 2019; Toth and Robinson 2005). We suspect that life stage was not significant due to our low sample size. The trends that we observed suggest that at least linoleic acid $(\omega 6)$ is higher in nurse heads and abdomens, which is consistent with previous findings (Corby-Harris et al. 2019; Toth and Robinson 2005).

Insect tissue EFAs can mirror dietary EFAs (Grau and Terriere 1971; Oonincx et al. 2020; Starčević et al. 2017). Manning (2001) speculated that this may be the case for honey bees and recent work confirms this (Arien et al. 2020, 2015). We therefore expected that bees fed the high-EFA supplement would have more EFAs in their tissues. In most cases, supplement type did not affect bee tissue EFAs. This relative constancy suggests that EFAs may be regulated metabolically, via absorption or secretion, or through behaviors that were not measured in this study such as reduced brood rearing (Arien et al. 2020) or brood cannibalism (Schmickl and Crailsheim 2001). This regulation hypothesis is further supported by the tissue $\omega 6: \omega 3$ ratios in supplement-fed hives, which were quite low $(\leq 1.08)$ compared to the supplements they consumed (high-EFA: $\omega 6: \omega 3=7.3$, low-EFA: $\omega 6: \omega 3=18.8)$. This suggests that bees somehow prioritize linolenic ( 13$)$ acid.

Recent work suggests that honey bee colonies forage in a manner that rescues previous EFA deficiencies and that balanced diets with lower $\omega 6: \omega 3$ ratios benefit honey bee health (Arien et al. 2018, 2020; Zarchin et al. 2017). We therefore hypothesized that bees fed low-EFA supplements would make more foraging visits to flours with more EFAs, especially those highest in linolenic ( $\omega 3)$ acid or with low $\omega 6: \omega 3$ ratios. This was not the case; supplement type did not influence choice flour preference. All hives preferred the white bean flour equally, followed closely by the red lentil and chickpea flours. Hives made more foraging visits to flours with smaller grain sizes and P:L ratios between $\sim 8$ and 13.4. In a survey of single source and bee-collected pollens, Vaudo et al. (2020) found that honey bees collected pollens with P:L ratios between $1: 1$ and 2:1. It is somewhat difficult to compare preference for pollen, a complex substance, to flour, a relatively simple substance. Features of the pollenkitt may enhance pollinator attraction irrespective of its true nutritional value to bees (Dobson 1988; Dobson and Bergström 2000), and this effect was removed here through the use of flours. Forager preference for higher P:L flours is also inconsistent with findings that younger bees prefer diets with lower P:L ratios and more fat, which improve health (Annoscia et al. 2017; Crone and Grozinger 2021; Pirk et al. 2010; Stabler et al. 2021). This discrepancy could be due to differences in experimental design (cages versus colonies) or because we looked at preference in older foragers and not younger bees.

We combined chemical analyses of supplements and bee tissues with observations of forager behavior to further understand supplemental bee nutrition and how dietary fatty acids are assimilated. Compared to natural pollen, the commercial pollen supplements we tested were low in linolenic ( $\omega 3)$ acid and were unbalanced in terms of their $\omega 6: \omega 3$ ratio. The two supplements chosen for further study differed in their linoleic ( $\omega 6)$ and linolenic $(\omega 3)$ acid levels and $\omega 6: \omega 3$ ratio. However, because (1) the bee tissue EFAs were relatively equal in the bees sampled from the low- and highEFA hives and (2) the tissue $\omega 6: \omega 3$ ratios were low (0.01-1.08) compared to the supplements were $>7$, we hypothesize that bees regulate tissue EFAs. Foragers did not change their behavior according to the supplement they were fed and all hives preferred flours with small grain sizes and high P:L ratios. Considering previous 
findings that hive function and health suffers when hives consume diets that are unbalanced and deficient in linolenic ( $\omega 3$ ) acid (Arien et al. 2018, 2020, 2015), we propose that pollen substitutes should be formulated with EFA levels in mind. This may be especially important if the behavioral or metabolic processes that enable fatty acid homeostasis are costly to hive health.

\section{SUPPLEMENTARY INFORMATION}

The online version contains supplementary material available at https://doi.org/10.1007/s13592-021-00896-0.

\section{ACKNOWLEDGEMENTS}

The authors are grateful to Vincent Ricigliano, Joe Rinehart, Harmen Hendriksma, and Sharoni Shafir for their comments on a previous version of this manuscript. We also acknowledge the University of Arizona Campus Agricultural Center Greenhouse Staff for maintaining the enclosures and handstitching the netting for the bays. The ARS/USDA is an equal opportunity employer and provider.

\section{AUTHOR CONTRIBUTION}

Conceptualization: Vanessa Corby-Harris; Methodology: Vanessa Corby-Harris, Mark J. Carroll, Meghan M. Bennett; Formal analysis and investigation: Vanessa Corby-Harris, Meghan M. Bennett, Mark J. Carroll; Writing — original draft preparation: Vanessa Corby-Harris; Writing — review and editing: Vanessa Corby-Harris, Meghan M. Bennett; Resources: Vanessa Corby-Harris, Mark J. Carroll; Supervision: Vanessa Corby-Harris. All authors read and approved the final manuscript.

\section{FUNDING}

This study was funded by internal funds from the USDAARS (Project Number: 2022-21000-017-00-D).

\section{CODE AVAILABILITY}

Not applicable.

\section{DECLARATIONS}

Ethics approval Not applicable.

Consent to participate Not applicable.

Consent for publication Not applicable.
Conflict of interest The authors declare no competing interests.

Open Access This article is licensed under a Creative Commons Attribution 4.0 International License, which permits use, sharing, adaptation, distribution and reproduction in any medium or format, as long as you give appropriate credit to the original author(s) and the source, provide a link to the Creative Commons licence, and indicate if changes were made. The images or other third party material in this article are included in the article's Creative Commons licence, unless indicated otherwise in a credit line to the material. If material is not included in the article's Creative Commons licence and your intended use is not permitted by statutory regulation or exceeds the permitted use, you will need to obtain permission directly from the copyright holder. To view a copy of this licence, visit http://creativecommons.org/ licenses/by/4.0/.

\section{REFERENCES}

Altaye, S.Z., Pirk, C.W.W., Crewe, R.M., Nicolson, S.W. (2010) Convergence of carbohydrate-biased intake targets in caged worker honeybees fed different protein sources. J. Exp. Biol. 213, 33113318. https://doi.org/10.1242/jeb.046953

Annoscia, D., Zanni, V., Galbraith, D., Quirici, A., Grozinger, C., Bortolomeazzi, R., Nazzi, F. (2017) Elucidating the mechanisms underlying the beneficial health effects of dietary pollen on honey bees (Apis mellifera) infested by Varroa mite ectoparasites Sci. Rep. 7, 6258. https:// doi.org/10.1038/s41598-017-06488-2

Arien, Y., Dag, A., Shafir, S. (2018) Omega-6:3 ratio more than absolute lipid level in diet affects associative learning in honey bees. Front. Psychol. 9, 1001. https://doi.org/10.3389/fpsyg.2018.01001

Arien, Y., Dag, A., Yona, S., Tietel, Z., Lapidot Cohen, T., Shafir, S. (2020) Effect of diet lipids and omega-6:3 ratio on honey bee brood development, adult survival and body composition. J. Insect Physiol. 124, 104074. https://doi.org/10.1016/j. jinsphys.2020.104074

Arien, Y., Dag, A., Zarchin, S., Masci, T., Shafir, S. (2015) Omega-3 deficiency impairs honey bee learning. Proc. Natl. Acad. Sci. USA. 112, 1576115766. https://doi.org/10.1073/pnas. 1517375112

Avni, D., Hendriksma, H.P., Dag, A., Uni, Z., Shafir, S. (2014) Nutritional aspects of honey bee-collected pollen and constraints on colony development in the eastern Mediterranean. J. Insect Physiol. 69, 65-73. https://doi.org/10.1016/j.jinsphys.2014. 07.001

Beekman, M., Preece, K., Schaerf, T.M. (2016) Dancing for their supper: Do honeybees adjust their recruitment dance in response to the protein content of 
Fatty acid homeostasis in honey bees (Apis mellifera) fed commercial diet supplements

pollen? Insectes. Sociaux. 63, 117-126. https://doi. org/10.1007/s00040-015-0443-1

Bonoan, R.E., O'Connor, L.D., Starks, P.T. (2018) Seasonality of honey bee (Apis mellifera) micronutrient supplementation and environmental limitation. J. Insect Physiol. 107, 23-28. https://doi.org/10. 1016/j.jinsphys.2018.02.002

Bonoan, R.E., et al. (2017) Seasonality of salt foraging in honey bees (Apis mellifera). Ecol. Entomol. 42, 195-201. https://doi.org/10.1111/een.12375

Brodschneider, R., Crailsheim, K. (2010) Nutrition and health in honey bees. Apidologie. 41, 278294. https://doi.org/10.1051/apido/2010012

Corby-Harris, V., Snyder, L., Meador, C. (2019) Fat body lipolysis connects poor nutrition to hypopharyngeal gland degradation in Apis mellifera. J. Insect Physiol. 116, 1-9. https://doi.org/10. 1016/j.jinsphys.2019.04.001

Corby-Harris, V., Snyder, L., Meador, C., Ayotte, T. (2018) Honey bee (Apis mellifera) nurses do not consume pollens based on their nutritional quality. PloS. One. 13, e0191050, https://doi.org/10.1371/ J..pone. 0191050

Cornman, R.S., Otto, C.R.V., Iwanowicz, D., Pettis, J.S. (2015) Taxonomic characterization of honey bee (Apis mellifera) pollen foraging based on non-overlapping paired-end sequencing of nuclear ribosomal loci. PloS. One. 10, e0145365. https://doi.org/10.1371/J.. pone. 0145365

Crailsheim, K. (1990) The protein balance of the honey bee worker. Apidologie. 21, 417-429

Crone MK, Grozinger CM (2021) Pollen protein and lipid content influence resilience to insecticides in honey bees (Apis mellifera). J. Exp. Biol 224 (9):jeb242040, https://doi.org/10.1242/jeb.242040

de Groot, A.P. (1953) Protein and amino acid requirements of the honeybee (Apis mellifica L.). Physiol. Comp. Oecol. 3, 197-285

DeGrandi-Hoffman, G., Chen, Y., Rivera, R., Carroll, M., Chambers, M., Hidalgo, G., de Jong, E.W. (2016) Honey bee colonies provided with natural forage have lower pathogen loads and higher overwinter survival than those fed protein supplements. Apidologie. 47, 186-196. https://doi.org/10.1007/ s13592-015-0386-6

DeGrandi-Hoffman, G., et al. (2021) The importance of time and place: Nutrient composition and utilization of seasonal pollens by European honey bees (Apis mellifera L.) Insects. 12, 235. https://doi.org/ $10.3390 /$ insects 12030235

DeGrandi-Hoffman, G. et al. (2018) Connecting the nutrient composition of seasonal pollens with changing nutritional needs of honey bee (Apis mellifera L.) colonies. J. Insect Physiol. 109(2018), 114-124. https://doi.org/10.1016/j.jinsphys.2018. 07.002

Dobson, H.E. (1988) Survey of pollen and pollenkitt lipids-chemical cues to flower visitors? Am. J. Botan. 75, 170-182
Dobson, H.E.M., Bergström, G. (2000) The ecology and evolution of pollen odors. Plant. Syst. Evol. 222, 63-87. https://doi.org/10.1007/BF00984096

Grau, P.A., Terriere, L.C. (1971) Fatty acid profile of the cabbage looper, Trichoplusia ni, and the effect of diet and rearing conditions. J. Insect Physiol. 17, 1637-1649. https://doi.org/10.1016/00221910(71)90059-X

Haydak, M.H. (1970) Honey bee nutrition. Ann. Rev. Entomol. 15, 143-156. https://doi.org/10.1146/ annurev.en.15.010170.001043

Hendriksma, H.P., Shafir, S. (2016) Honey bee foragers balance colony nutritional deficiencies. Behav. Ecol. Sociobiol. 70, 509-517

Hendriksma, H.P., Toth, A.L., Shafir, S. (2019) Individual and colony level foraging decisions of bumble bees and honey bees in relation to balancing of nutrient needs. Front. Ecol. Evol. https://doi.org/ 10.3389/fevo.2019.00177

Herbert, E.W., Shimanuki, H., Caron, D. (1977) Optimum protein levels required by honey bees (Hymentoptera, Apidae) to initiate and maintain brood rearing. Apidologie. 8, 141-146

Höcherl, N., Siede, R., Illies, I., Gätschenberger, H., Tautz, J. (2012) Evaluation of the nutritive value of maize for honey bees. J. Insect. Physiol. 58, 278-285. https://doi.org/10.1016/j.jinsphys.2011. 12.001

Leonhardt, S.D., Blüthgen, N. (2012) The same, but different: pollen foraging in honeybee and bumblebee colonies. Apidologie. 43, 449-464. https://doi.org/ 10.1007/s13592-011-0112-y

Lunau, K. (2000) The ecology and evolution of visual pollen signals. Plant. Syst. Evol. 222, 89-111. https://doi.org/10.1007/BF00984097

Lundin, O., Ward, K.L., Williams, N.M. (2019) Identifying native plants for coordinated habitat management of arthropod pollinators, herbivores and natural enemies J. Appl. Ecol. 56, 665-676. https://doi. org/10.1111/1365-2664.13304

Manning, R. (2001) Fatty acids in pollen: a review of their importance for honey bees. Bee. World. 82, 60-75. https://doi.org/10.1080/0005772X.2001. 11099504

Manning, R. (2008) The effect of high and low fat pollens on honeybee longevity. RIRDC Publication No. 08/031 Department of Agriculture Western Australia

Manning, R. (2018) Artificial feeding of honeybees based on an understanding of nutritional principles. Anim. Prod. Sci. 58, 689-703. https://doi.org/ 10.1071/AN15814

Manning, R., Rutkay, A., Eaton, L., Dell, B. (2007) Lipid-enhanced pollen and lipid-reduced flour diets and their effect on the longevity of honey bees (Apis mellifera L.). Australian. J. Entomol. 46, 251-257. https://doi.org/10.1111/j.1440-6055. 2007.00598.x 
McMinn-Sauder, H., Richardson, R., Eaton, T., Smith, M., Johnson, R. (2020) Flowers in Conservation Reserve Program (CRP) pollinator plantings and the Upper Midwest agricultural landscape supporting honey bees. Insects. 11, 405

Melin, A., Colville, J.F., Duckworth, G.D., Altwegg, R., Slabbert, R., et al. (2020) Diversity of pollen sources used by managed honey bees in variegated landscapes J. Apic. Res. 59(5), 988-999. https://doi.org/10.1080/ 00218839.2020 .1750757

Oksanen, J., et al. (2020) vegan: Community Ecology Package

Oonincx, D.G.A.B., Laurent, S., Veenenbos, M.E., van Loon, J.J.A. (2020) Dietary enrichment of edible insects with omega 3 fatty acids. Insect Sci. 27, 500-509. https://doi.org/10.1111/1744-7917. 12669

Paoli, P.P., Donley, D., Stabler, D., Saseendranath, A., Nicolson, S.W., et al. (2014) Nutritional balance of essential amino acids and carbohydrates of the adult worker honeybee depends on age. Amino. Acids. 46, 1449-1458. https://doi.org/10.1007/ s00726-014-1706-2

Pernal, S.F., Currie, R.W. (2001) The influence of pollen quality on foraging behavior in honeybees (Apis mellifera L.). Behav. Ecol. Sociobiol. 51, 53-68. https://doi.org/10.1007/s002650100412

Pernal, S.F., Currie, R.W. (2002) Discrimination and preferences for pollen-based cues by foraging honeybees, Apis mellifera L. Anim. Behav. 63, 369-390. https://doi.org/10.1006/anbe.2001.1904

Pirk, C.W.W., Boodhoo, C., Human, H., Nicolson, S.W. (2010) The importance of protein type and protein to carbohydrate ratio for survival and ovarian activation of caged honeybees (Apis mellifera scutellata). Apidologie. 41, 62-72. https://doi.org/10. 1051/apido/2009055

Richardson, R.T., et al. (2019) Quantitative multilocus metabarcoding and waggle dance interpretation reveal honey bee spring foraging patterns in Midwest agroecosystems Mol. Ecol. 28, 686697. https://doi.org/10.1111/mec.14975

Robinson, F.A., Nation, J.L. (1970) Long-chain fatty acids in honeybees in relation to sex, caste, and food during development. J. Apicult. Res. 9, 121-127. https://doi. org/10.1080/00218839.1970.11100258

Roulston, T., Cane, J.H. (2000) Pollen nutritional content and digestibility for animals. In: Dafni, A., Hesse, M., Pacini, E. (Eds.) Pollen and Pollination. Springer Vienna, Vienna, pp. 187-209. https://doi. org/10.1007/978-3-7091-6306-1_10

Rowe, L., Gibson, D., Bahlai, C.A., Gibbs, J., Landis, D.A., Isaacs, R. (2020) Flower traits associated with the visitation patterns of bees. Oecologia. 193, 511522. https://doi.org/10.1007/s00442-020-04674-0

Saa-Otero, M.P., Díaz-Losada, E., Fernández-Gómez, E. (2000) Analysis of fatty acids, proteins and ethereal extract in honeybee pollen - considerations of their floral origin. Grana. 39, 175-181. https://doi. org/10.1080/00173130051084287

Schmickl, T., Crailsheim, K. (2001) Cannibalism and early capping: strategy of honeybee colonies in times of experimental pollen shortages J. Comp. Physiol. A. 187, 541-547

Seppänen-Laakso, T., Laakso, I., Hiltunen, R. (2002) Analysis of fatty acids by gas chromatography, and its relevance to research on health and nutrition. Anal. Chimica. Acta. 465, 39-62

Smart, M.D., Cornman, R.S., Iwanowicz, D.D., McDermottKubeczko, M., Pettis, J.S., et al. (2017) A comparison of honey bee-collected pollen from working agricultural lands using light microscopy and ITS metabarcoding. Environ. Entomol. 46, 38-49. https://doi.org/ 10.1093/ee/nvw159

Somerville, D. (2005) Fat bees skinny bees: A manual on honey bee nutrition for beekeepers. Australian Government Rural Industries Research and Development Corporation.

Stabler, D., Al-Esawy, M., Chennells, J.A., Perri, G., Robinson, A., Wright, G.A. (2021) Regulation of dietary intake of protein and lipid by nurseage adult worker honeybees. J. Exp. Biol. 224, jeb230615. https://doi.org/10.1242/jeb.230615

Standifer, L.N. (1967) A comparison of the protein quality of pollens for growth-stimulation of the hypopharyngeal glands and longevity of honey bees, Apis mellifera L. (Hymenoptera: Apidae). Insectes. Sociaux. 14, 415-425. https://doi.org/ 10.1007/bf02223687

Starčević, K., Gavrilović, A., Gottstein, Ž., Mašek, T. (2017) Influence of substitution of sunflower oil by different oils on the growth, survival rate and fatty acid composition of Jamaican field cricket (Gryllus assimilis). Anim. Feed Sci. Technol. 228, 66-71. https://doi.org/10.1016/j.anifeedsci.2017. 04.007

Toth, A.L., Robinson, G.E. (2005) Worker nutrition and division of labour in honeybees Anim. Behav. 69, 427-435. https://doi.org/10.1016/j.anbehav.2004. 03.017

van der Moezel, P.G., Delfs, J.C., Pate, J.S., Loneragan, W.A., Bell, D.T. (1987) Pollen selection by honeybees in shrublands of the northern sandplains of western Australia. J. Apic. Res. 26, 224-232. https:// doi.org/10.1080/00218839.1987.11100764

Van Handel, E. (1985) Rapid determination of total lipids in mosquitoes J. Am. Mosquito Control Assoc. 1, 302-304

Vanderplanck, M., Zerck, P.-L., Lognay, G., Michez, D. (2020) Sterol addition during pollen collection by bees: Another possible strategy to balance nutrient deficiencies? Apidologie. https://doi.org/10.1007/ s13592-020-00764-3

Vaudo, A.D., et al. (2020) Pollen protein:lipid macronutrient ratios may guide broad patterns of bee species floral preferences. Insects. 11, 132 
Fatty acid homeostasis in honey bees (Apis mellifera) fed commercial diet supplements

Wright, G.A., Nicolson, S.W., Shafir, S. (2018) Nutritional physiology and ecology of honey bees. Ann. Rev. Entomol. 63, 327-344. https://doi.org/10. 1146/annurev-ento-020117-043423

Zarchin, S., Dag, A., Salomon, M., Hendriksma, H.P., Shafir, S. (2017) Honey bees dance faster for pollen that complements colony essential fatty acid deficiency. Behav. Ecol. Sociobiol. 71(12), 172. https://doi.org/10.1007/s00265-017-2394-1

Publisher's Note Springer Nature remains neutral with regard to jurisdictional claims in published maps and institutional affiliations. 